\title{
LA ÉCFRASIS EN EL SIGLO XV: MARAVILLA, METATEXTO Y ALEGORÍA
}

\author{
Barry TAYLOR \\ British Library \\ Barry.taylor@bl.uk
}

\section{Teoría y práctica}

La écfrasis, generalmente definida como la descripción literaria de un objeto de arte, se practica desde la Antigüedad: el ejemplo más citado por la crítica es el del Escudo de Aquiles (Ilíada, XVIII, 478-608):

En el escudo, de las quales armas el potente Vulcano esculpiera o de elevadas imágines entallara toda la máchina y fechura mundana, a bueltas con el alto firmamento y cielo sembrado de varias y luminosas estrellas [...] Y allí pintara las bozes de los años y los tiempos de la noche y la su non igual medida [...] Era más figurado en el escudo: cómo las greyes y manadas de los ganados tundían los prados verdes y cómo las cabras se colgavan y saltavan por los peñedos $[\ldots]^{1}$.

Un pasaje que quizás conocían mejor los autores castellanos del siglo Xv, que son el centro de atención de este estudio, es el Escudo de Eneas (Eneida, VIII, 626-731)

Estaba allí estampado el gran linaje

$\mathrm{Y}$ descendencia toda desde Ascanio

Y todas, por su orden, las batallas. [...]

\footnotetext{
${ }^{1}$ Omero romançado, traducido por Juan de Mena, en Juan de Mena, Obra completa, ed. de Ángel Gómez Moreno y Teresa Jiménez Calvente, Biblioteca Castro, Madrid, Turner, 1994, cap. XXX, pp. 591-92. 'Voces' es probablemente error de copia por 'veces', pero como veremos es propio de la écfrasis expresar contenido (por ejemplo los sonidos) que lógicamente no puede caber en un objeto plástico.
} 
La historia expuesta aquí se extiende hasta la batalla de Accio, contemporánea del autor:

Estaba de una parte el divo Augusto, Gran capitán de la romana armada [...]

Aquesto todo contemplaba Eneas

Maravillado en el insigne escudo,

Don de su madre y de Vulcano,

$\mathrm{Y}$, aunque ignorante de los que el entalle

Daba a entender, tomaba extraño gusto

Sólo mirando la pintura muda $[\ldots]^{2}$.

En estos dos pasajes se ve un constante de la écfrasis: los dos escudos engloban material que lógicamente excede las capacidades fisicas de un artefacto. La crítica no es unánime respecto a la función del escudo de Homero. ${ }^{3}$ En contraste, la función del escudo de Virgilio (poeta áulico) está clara. Eneas presencia la historia de los troyanos, pero no aprecia que lo que tiene ante los ojos es una profecía y amonestamiento a cumplir en torno a la historia de su pueblo ${ }^{4}$.

Un hito en el estudio de la écfrasis fueron dos trabajos iconoclastas de Ruth Webb ${ }^{5}$. Como demuestra esta autora, el uso de écfrasis para referirse a un género o subgénero no se remonta más allá de la obra de Leo Spitzer en los años cincuenta del siglo xx. La écfrasis, tal como la concebimos hoy, tiene poca presencia en la retórica antigua. Es cierto que existen descripciones de obras de arte entre los Progymnasmata (ejercicios de retórica) griegos. Pero está probado que tales escritos estaban pensados para encarnar un concepto más amplio de la vívida descripción (enargeia o evidentia, que 'pone el material delante de los ojos') que podía tratar de objetos pero también de personas e incluso acciones, por ejemplo las batallas y las tormentas. El texto maestro de la écfrasis, las Imagines de Filostrato, que consiste precisamente en descripciones de obras de arte, se integra dentro de este concepto lato de la enargeia (para mí la existencia de obras postmedievales que consisten exclusivamente en descripciones de obras de arte como la Galleria de Marino

\footnotetext{
${ }^{2}$ Virgilio, La Eneida, traducción de Gregorio Hernández de Velasco [1555], Barcelona, Planeta, 1982, pp. 311-317.

${ }^{3}$ James A. W. Heffernan, Museun of Words: The Poetics of Ekphrasis from Homer to Ashbery, Chicago, University Press, 1993, pp. 10-21.

${ }^{4}$ María Emilia Cairo, «El escudo de Vulcano: écfrasis y profecía en Eneida 8», en Myrtia, 28 (2013), pp. $105-28$

${ }^{5}$ Ruth Webb, «Ekphrasis Ancient and Modern: The Invention of a Genre», en Word \& Image, 15 (1999), pp. 7-18 y Ekphrasis, Imagination and Persuasion in Ancient Rhetorical Theory and Practice, Aldershot, Ashgate, 2009.
} 
es prueba evidente de que existía un concepto de écfrasis precisamente tal y como la había definido Spitzer).

Todo el corpus de manuales retóricos, desde el auctor ad Herennium a Godofredo de Vinsauf, hasta Lausberg y el Historisches Wörterbuch der Rhetorik, conocen la evidentia pero no la écfrasis ${ }^{6}$. Así se explica la ausencia del término e incluso del concepto de écfrasis en los tratadistas españoles. Miremos por ejempo lo que dice Hernán Núñez del trono de Juan II en el Laberinto de Fortuna?:
Alli sobre todos Fortuna pusiera
al muy prepotente don Juan el segundo [...]
y él en una silla tan rica labrada
como si Dédalo bien la hiziera (copla 141).

Queriendo tratar de las guerras de España, pone en el principio y cabecera sobre todos al rey don Juan, y dize que le vido en el lugar más pujante y principal, armado de resplandecientes armas, con una relumbrante espada ceñida al lado y sentado en una silla labrada de muy rica maçonería.

En su autoexégesis de la Coronación, Mena no hace ninguna referencia al género cuando describe los tronos de los Electos en el Parnaso:

De grande estrado de rosas
vi la fuente çircundada
y de sillas muy fermosas,
a menos de otras cosas
en torno bien ordenada;
sillas de ricas labores,
vacantes de sus señores,
vi de fieras esculpidas,
sin otras que vi guarnidas
de muy prudentes actores (copla 35 ).

vi de fieras esculpidas: conviene a saber de animalias bestias fieras figuradas

\footnotetext{
${ }^{6}$ Rhetorica ad Herennium, ed. y trad. de Harry Caplan, Cambridge, MA, Loeb Classical Library, 1954, IV.lv, pp. 404-405; Godofredo de Vinsauf, Poetria nova, ed. y trad. de Ana María Calvo Revilla, Madrid, Arco, 2008, descriptio pp. 159-65, versos 559-672; Heinrich Lausberg, Elementos de retórica literaria, trad. de Mariano Marín Casero, Madrid, Gredos, 1975, §369, pp. 179-80; A. Kemmann, «Evidentia», en Historisches Wörterbuch der Rhetorik, ed. de Gert Ueding, Bd. 3, Tübingen, De Gruyter, 1996, cols. 33-48.

${ }^{7}$ Hernán Núñez de Toledo, Glosa sobre las «Trezientas» del famoso poeta Juan de Mena, ed. de Julian Weiss y Antonio Cortijo Ocaña, Madrid, Polifemo, 2015.
} 


\section{Barry TAYLOR}

e entretalladas, e esto más está aquí por afermosar la palabra que non por la inportançia que trahe ${ }^{8}$.

De la misma manera, Fernando de Herrera, muy amigo de los términos genéricos, al comentar el pasaje de la Egloga II, 105-272 garcilasiana en el que el poeta, siguiendo el modelo de Ovidio en las Metamorfosis, describe los tapices que tejen las ninfas, no hace ningún comentario al género al que pertenece este tipo de descripción 9 .

Sin embargo, la teoría no se corresponde a la práctica. Es evidente que los escritores sí escribían écfrases, y que seguían modelos y no preceptos.

Aunque los teóricos no hablan de la écfrasis, en sus obras se encuentran dos términos que pueden solaparse con ella y que, por lo tanto, serán usados en este estudio.

La primera es la personificación, prosopopeia alias effictio:

But if ye will feign any person with such features, qualities and conditions, or if ye will attribute any human quality, as reason or speech, to dumb creatures or other insensible things, and do study (as one may say) to give them a human person, it is not prosopographia, but prosopopeia, because it is by way of fiction. And no prettier examples can be given to you thereof than in the Romaunt of the Rose, translated out of French by Chaucer, describing the persons of Avarice, Envy, Old Age, and many others, wherein much morality is taught ${ }^{10}$.

La segunda figura se llama topothesia, es decir, la descripción de un sitio imaginario. El término es clásico, ya que Servio lo emplea al comentar la Eneida 1.159 («Est in secessu longo locus [...]»): 'topothesia est, id est fictus secundum poeticam licentiam locus' (ad Aen. $)^{11}$.

Erasmo da una explicación más desarrollada en el De copia:

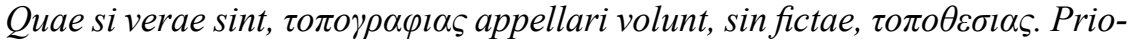
ris formae sunt: Carthiginis et portus apud Maronem descriptio; apud Plinium in Epistolis Laurentis villae; apud Statium Surretinum Polii et Tibertinum Manlii; posterioris: sedes Somni apud Ouidium; domus Famae et regia

\footnotetext{
${ }^{8}$ Citado en Barry Taylor, «Juan de Mena, la écfrasis y las dos fortunas: Laberinto de Fortuna, 143208», en Revista de Literatura Medieval, 6 (1994), pp. 171-81, cita p. 172.

${ }^{9}$ Véase Herrera, en Garcilaso de la Vega y sus comentaristas, ed. de Antonio Gallego Morrell, Madrid, Gredos, 1972, H-790-813.

${ }^{10}$ George Puttenham, The Art of English Poesy, ed. de Frank Whigham y Wayne A. Rebhorn, Ithaca, Cornell University Press, 2007, p. 324. He modernizado la ortografía. Cfr. Rhetorica ad Herennium, p. 387 (effictio).

${ }^{11}$ Ibídem, pp. 324-25.
} 
Solis apud eundem; inferorum et Caci domus apud Vergilium; Tenari apud Statium; domus apud Lucianum; regia Psyches apud Apuleium.

[Si estas descripciones son verdaderas, se llaman topografías; si fingidas, topothesias. De la primera forma son: la descripción de Cartago y su puerto en Virgilio; la de su vila laurentina en las epístolas de Plinio; la de Estacio de la vila de Polio en Sorrento y la vila de Manlio en Tívoli. Las fingidas incluyen: la Casa del Sueño en Ovidio; la Casa de la Fama, el Palacio del Sol en el mismo autor [Met. $11.592 \mathrm{ss} ; 12.39 \mathrm{ss} ; 2.1 \mathrm{ss}$ ]; la del infierno y de la casa de Caco en Virgilio [Aen. 6.268; 8. 225 ss]; de Taenarum en Estacio [Thebaida 2.32 ss]; la casa en Luciano [De domo]; y el palacio de Psique en Apuleyo $[5.1-2]^{12}$.

Si la écfrasis tiene poca presencia entre los teóricos españoles, la topotesia es solo mínimamente más difundida: la encuentro solo en la Retórica en lengua castellana de Miguel de Salinas (1541), muy endeudada con el De copia erasmiano ${ }^{13}$.

Como veremos, existe una íntima relación entre estas tres figuras. ¿Dónde viven las personificaciones si no es en una topotesia? Y ¿cómo se decoran estos sitios imaginados si no es con écfrases, descripciones de objetos de arte, que en su mayoría presentan información visual de carácter alegórico?

\section{La práctica: textos medievales no hispánicos}

Pasemos ahora revista a una selección de textos medievales que demuestran écfrasis, prosopopeya y topotesia.

En un estudio clásico, Söhring saca a luz una riqueza de écfrases en las chansons de geste francesas ${ }^{14}$. Entre los objetos plásticos descritos se incluyen: torres (p. 505), palacios (p. 511), monumentos religiosos (p. 522), templos antiguos (p. 524), tumbas (p. 526), orfebrería (p. 544), mesas (p. 544), bandejas (p. 544), camas (p. 547), copas (p. 552), cuernos (p. 553), armaduras de hombre y caballo (p. 563), relieves (p. 565), fuentes (p. 570), textiles (p. 598), pinturas murales (p. 599), objetos de vidrio (p. 607), paneles, retratos (p. 607), sellos (p. 611), escudos (p. 612), tapices (p. 614), vestidos (pp. 618 y 621), mitras (p. 622), y tiendas de campaña (p. 623).

${ }^{12}$ Erasmo, De copia verborum ac rerum, ed. de Betty I. Knott, Opera omnia Desiderii Erasmi Roterodami, Ordo I, tom. 6, Amsterdam, North-Holland, 1988, p. 214.

${ }^{13}$ Miguel de Salinas, Rhetorica en lengua castellana, ed. de Encarnación Sánchez García, Napoli, L'Orientale, 1999, pp. 41-42.

${ }^{14}$ Otto Söhring, «Werke bildender Kunst in altfranzösischen Epen», en Romanische Forschungen, 12 (1900), pp. 491-640. Hay un sumario por orden cronológico en pp. 635-640. 
De los elementos decorativos, los más difundidos son los elementos narrativos:

Où ymages taillées y avoit de Rolant, de tous les .XII. pers, d'Olivier le poissant; comment furent venus à Marsille le grant et dedens Roncevaux occis en combatant

(en una bandeja: pp. 545 y 555).

Se muestran episodios de la guerra de Troya (p. 621); de los romans artúricos (p. 622) y de historia bíblica (p. 633). Dichos elementos mayoritariamente son de naturaleza bélica ${ }^{15}$. La frase recurrente «[se veía] cómo» deja constancia de que estas imágenes eran capaces de expresar tanto la narrativa como el movimiento. La presencia de las escenas de batallas recuerda que en los textos clásicos la temática en la que mejor se expresaba la evidentia eran las hazañas bélicas ${ }^{16}$.

También se dan varios ejemplos de temas cósmicos: las esferas (pp. 565, 601 y 612), las tormentas (p. 566), los elementos (p. 617), la geografía (pp. 625 y 626). Incluso el tiempo se expresa visualmente: los doce meses (pp. $605,606,617,627$ y 628$)^{17}$.

Otro tema predilecto son las siete artes liberales, como conjunto «et enlevee les set arz», o individualmente ${ }^{18}$.

[Aritmética] Si com ele nombre par sans

Les jorz et les ores del tans,

Et l'eue de mer gote a gote (p. 620)

No faltan referencias al realismo de dichas imágenes: «Et ymages d'autre figure / qui samblent vives par nature» ${ }^{19}$.

Asimismo, cabe citar un ejemplo en el que la viveza de la imágen es tan convincente que incluso el sonido parece sentirse:

Une image i ot tresgetee

Que vait cornant a la menee;

${ }^{15}$ Véanse también: p. 555 (dos ejemplos), p. 557 (dos ejemplos), p. 558, p. 564 (dos ejemplos), p. 565 n, p. 566 , p. 600 , p. 601 , p. 602 , p. 603 , p. 604 , p. 608 , p. 616 , p. 618 , p. 625 (batallas), p. 628 (historia).

${ }^{16}$ Ruth Webb, «Ekphrasis Ancient and Modern: The Invention of a Genre», art. cit., pp. 8 y 12.

${ }^{17}$ Otto Söhring, «Werke bildender Kunst in altfranzösischen Epen», art. cit.

${ }^{18}$ Ibídem, p. 567; cfr. pp. 605, 606 y 616.

${ }^{19}$ Ibidem, p. 513; cfr. p. 601 y 603. 
Une autre, que toz tens frestèle

Plus cler que rote ne vièle (p. 567)

A diferencia de lo que hallaremos en otros géneros, en las chansons de geste las figuras mitológicas o alegóricas no son frecuentes: se encuentran dioses y retratos (p. 571) y unos alegóricos Cupido (p. 604) y Venus (p. 605).

En otros tipos de texto podemos localizar inscripciones: «Et sus cascun fait fu une lettre dictée, / Qui devisoit comment li cose estoit alée» (p. 608).

El carácter sobrenatural del arte se atribuye a la intervención de las hadas:

Treis faees serors la firent,
En une chambre la tissirent;
Chascune d'els s'i essaia
Et son saveir i demostra
Et firent i peissons marages,
Oisels volanz, beste salvages

(p. 619; cfr. pp. 617, 620 y 631).

Söhring demuestra a la perfección cómo el Roman d'Alexandre reúne un número relativamente alto de estos elementos: un mapamundi, los doce meses, las historias de Elena y de Hércules, las horas y los días, y los planetas. Cuando Alejandro ve el mundo en una écfrasis, comenta (como Cipión en el Somnium Scipionis) que lo encuentra muy pequeño. Y cuando mira la Guerra de Troya retratada en la pared de una tienda, esto le inspira el deseo de conquista: «Del roiaume de Perse ferai itel ruine, / Et mettrai le roi Daire en itel desepline» ${ }^{20}$.

Considero que aquí el Roman recoge un elemento de la écfrasis que existía en el mundo clásico (lo hemos visto en el Escudo de Eneas) pero me parece que no se conocía en la literatura medieval hasta este momento: me refiero a la lección y la profecía. En los otros textos que estudia Söhring las écfrases funcionan como meros excursos: la del Roman influye directamente en el desarrollo de la trama.

En el Anticlaudianus (compuesto hacia 1181-1184) de Alano de Lille, la écfrasis desempeña un papel prioritario ${ }^{21}$. Las ropas de las Virtudes y Ciencias personificadas están ilustradas con doctrinas (bastante abstractas) y retratos de figuras ejemplares.

${ }^{20}$ Ibídem, pp. 628-631, cita p. 631.

${ }^{21}$ Dos autores peninsulares sintieron la influencia del Anticlaudianus, véanse J. P. Wickersham Crawford, «The Seven Liberal Arts in the Vision delectable of Alfonso de la Torre», en Romanic Review, 4 (1913), pp. 58-75 y Bernat Metge, Llibre de Fortuna i Prudència, ed. de Lluís Cabré, Els nostres clàssics, B30, Barcelona, Barcino. 2010, pp. 24-41. 


\section{Barry TAYLOR}

On the garment the following are inscribed and show forth their description: the force, nature, power, order, matter, divisions, purpose, title and author, function, species, genus, tools and capacity of the art of grammar [...] Here was to be seen how in poetry a vowel in conflict with another vowel melts away and loses the honour of being sounded; how in poetry a letter loses its natural strength and its force, banished for a time, languishes [...] This series of pictures painted successively drenches the eyes with delight and serves the mind a feast. A very talented painter had painted it, or rather one more powerful than any painter, and the painting proclaims his skill $[\ldots]^{22}$.

vestibus hec inscripta manent, descripta resultant,

artis grammatice uirtus, natura, potestas,

ordo, materies, pars, finis, nomem et actor.

officium, species, genus, instumenta, facultas.

[...]

qualiter in metro secum rixata liquescat

vocalis uocisque suum deperdat honorem;

qualiter in metro natiuas littera uires

perdit et ad tempus langet proscripta potestas

[...]

hec artis series seriatim picta propinat

delicias oculis et menti fercula donat,

nam pictor predoctus eam descripserat, immo

plus pictore potens, picturaque clamitat illum ${ }^{23}$.

Estas doncellas construyen un carro decorado con imágenes. La Gramática aporta écfrases de figuras relevantes de su campo como Donato, Aristarco, Díndimo, Prisciano ${ }^{24}$.

La Casa de Fortuna merece especial atención por la influencia que ejerció en otros autores medievales.

The house of Fortune, clinging on high to a sheer rock and threatening to tumble down, sinks into a steep slope. It is subject to every raging wind and bears the brunt of every tempest of heaven. Rarely does the gentle breeze of Zephyrus make that house calm and clear and rather seldom does its soft, kind breath wipe out the storms of Notus and the cold of Boreas. One part of the house sits atop the mountain rock, the other crouches on the rock's base and

${ }^{22}$ Alan of Lille, Anticlaudianus, trad. de James J. Sheridan, Toronto, Pontifical Institute of Mediaeval Studies, 1973, pp. 85-89.

${ }^{23}$ Alain de Lille, Anticlaudianus, ed. de R. Bossuat, Paris, Vrin, 1955, citas respectivamente II, vv. 415-418, vv. 440-443 y vv. 472-475

${ }^{24}$ Alan of Lille, Anticlaudianus, trad. de James J. Sheridan, ed. cit., pp. 89-90, vv. 486-513. 
as though on the verge of sliding off, shows signs of falling. One part of the house glitters with silver, shines with gems, is alight with gold; the other part lies debased with worthless material ${ }^{25}$.

Rupis in abrupto suspensa minansque ruinam,
Fortune domus in preceps descendit, et omnem
ventorum patitur rabiem celique procellas
sustinet, et raro Zephyri mansueta serenat
aura domum flatusque Notho Boreeque rigorem
parcius abstergit lenis clemencia flatus.
Pars in monte sedet, pars altera montis in imo
subsidet, et casum tanquam lapsura minatur.
Fulgurat argento, gemmis splendescit et auro
resplendet pars una domus; pars altera uili
materie deiecta iacet; pars ista superbit
culmine sublimi, pars illa fatiscit hiatu ${ }^{26}$.

Alano describe su casa, la figura de Fortuna misma y su rueda. Introduce el tema de la rueda ex abrupto: «She keeps her wheel in fast motion and no rest brings an end to the toil of movement» [succurrit motumque rote uelocius urget] (VIII, 51). Pero el poeta no explica con detalle dónde se localiza la rueda en relación con la casa.

A mi modo de ver, la práctica ecfrástica se extiende a episodios no visuales. Observo un paralelismo entre las frases con «qualiter» en los versos 440443, citados arriba, y «As she passes through the regions of Air, Prudence [...] asks herself: what is the material and origin of the clouds; in what way the earth, damp with its own moisture, sends exudations to form clouds and arranges a mantle for itself in the heavens [...]», p. 126 [aeris aggrediens tractus prudencia caute [...] inquirit que materies, que nubis origo, / quomodo terra madens proprio sudore resudat/ in nubes celoque suos componit amictus] (IV, vv. 245-249).

El Roman de la Rose (1237-1277) es famosa por sus personificaciones, presentadas con tanto detalle y psicologismo que parecen personajes reales ${ }^{27}$. Para el presente estudio es interesante llamar la atención sobre la topothesia del jardín de Deduit (Placer), rodeado de un muro cuya cara exterior muestra los vicios que están excluidos:

${ }^{25}$ Ibidem, VIII, p. 189.

${ }^{26}$ Alain de Lille, Anticlaudianus, ed. de R. Bossuat, ed. cit., VIII, vv. 1-12.

${ }^{27}$ Frederick Bliss Luquiens, «The Roman de la Rose and Medieval Spanish Literature», en Romanische Forschungen, 20 (1907), pp. 284-320, el único estudio sobre el tema que se centra casi exclusivamente en el tratamiento de la naturaleza y poco o nada trata sobre las alegorías. 
quant j'oi un poi avant alé, si vi un vergier grant et lé, tot clos de haut mur bataillé, portrait dehors e entaillié a maintes riches escritures.

[...] enz en le milieu vi Haïne, qui de corroz e d'ataïne sembla bien estre moveresse; corroceuse e tençoneresse, e pleine de grant cuvertage estoit par semblant cele image ${ }^{28}$.

La Mutacion de Fortune de Christine de Pizan, fechada en 1403, puede considerarse como representante típico del extenso poema moral que echa mano de la historia como recurso ejemplar. La autora describe el Castillo de Fortuna, en movimiento constante, construido sobre una roca alta, azotada por los vientos (Parte II) (la relación con el Anticlaudianus es obvia). Las pinturas que adornan el exterior se describen muy brevemente: «d'or et d'azur moult richement / maintes estranges pourtraitures, / pour aviser les creatures, / qui par la vont passant leur voye» ${ }^{29}$. La fuente es el Roman de la Rose.

La écfrasis más desarrollada del texto se localiza en el alto «Donjon» del Castillo de Fortuna, ornado con pinturas murales que muestran a los que han sido afectados por la Fortuna, también la filosofía, las ciencias y la historia del mundo desde la Creación hasta el presente (Partes IV-VII):

si est painte moult richement

d'or et d'azur trestout autour

et par les pillers fais a tour;

si sont la escriptes les gestes

des grans princes et les conquestes ${ }^{30}$.

La Hypnerotomachia Poliphili de Francesco Colonna (impresa en 1499), merece mención porque hizo época en la historia de la écfrasis, aunque quizás resultaron más influyentes los 168 grabados, elaborados expresamente

${ }^{28}$ Le Roman de la Rose par Guillaume de Lorris et Jean de Meun, ed. de Ernest Langlois, SATF, Paris, Firmin-Didot, 1914-1924, cita vv. 129-133 y 139-143; II, pp. 7-8.

${ }^{29}$ Christine de Pisan, Le Livre de la mutacion de Fortune, ed. de Suzanne Solente, 4 vols., SATF, Paris, Picard, 1959-1966, cita vv. 1581-1583.

${ }^{30}$ Ibidem, vv. 7104-7108. 
para acompañar el texto (comunmente tildado de «ilegible» por la crítica) ${ }^{31}$. En esta obra se describen objetos plásticos de todo tipo: templos, obeliscos, estatuas, carros. Cabe notar la cualidad enigmática de la Hypnerotomachia, ya que alguna inscripción está escrita en jeroglíficos. Para Dronke «Much that was distinctive in the Roman de la Rose had, in the period between Jean de Meun and Francesco Colonna, become part of the common heritage of medieval allegories of love $)^{32}$.

A mi entender, en estos textos pueden distinguirse una serie de elementos recurrentes que paso a comentar.

La écfrasis, que «pone el material delante de los ojos», por su carácter visual está en estrecha relación con la alegoría y el sueño-visión.

La écfrasis puede ser en ciertos casos un simple elemento decorativo o digresión, pero en otros funciona como un metatexto que es la clave de toda la obra: piénsese en el escudo profético de Eneas (Eneida VIII, 626-731) ${ }^{33}$ y las esculturas exteriores del Roman de la Rose; la contemplación de la Guerra de Troya inspira a Alejandro a realizar más conquistas.

La écfrasis inspira la maravilla, bien por la destreza con la que se construye, bien por los materiales exóticos con los que se elabora: la tumba de Camila «ki peinte ert de mainte color, / a or, a pierres tot entor» ${ }^{34}$.

La écfrasis olvida que es una obra de arte: desde Homero se retratan movimientos o se incluye demasiado material para caber en el recipiente (como comentó Lessing a propósito del Laokoon) $)^{35}$; cuando el poeta dice «Vi cómo $[\ldots] \gg \mathrm{o}$ «Se veía cómo $[\ldots] »$, el lector no sabe si se trata de una acción o de una imagen de dicha acción. Una vez introducido el esquema pictórico del Donjon de Fortuna, Christine de Pizan rara vez se refiere al elemento plástico. Para mí es interesante subrayar que Pizan solo nos recuerda que estamos leyendo imágenes cuando necesita hacer la transición entre periodos históricos. Por ejemplo, al llegar a la caída de Persia, resume lo que ha visto en la pared:

\footnotetext{
${ }^{31}$ Francesco Colonna, Hypnerotomachia Poliphili (Venetiis, Aldo Manuzio, 1499), introd. de Peter Dronke, Zaragoza, Ediciones del Pórtico, 1981, p. 10. La crítica no ha rastreado la influencia de la Hypnerotomachia en la literatura española, pero en las artes visuales siete de sus grabados se copiaron en el claustro de la Universidad de Salamanca, véase S. Sebastián y L. Cortés, Simbolismo de los programas humanisticos de la Universidad de Salamanca, Salamanca, Universidad de Salamanca, 1973.

${ }^{32}$ Francesco Colonna, Hypnerotomachia Poliphili (Venetiis, Aldo Manuzio, 1499), ed. cit., p. 62.

${ }^{33}$ Sobre la écfrasis profética en la tradición clásica, véase Vicente Cristóbal, «De la Eneida a la Araucana», en Cuadernos de Filología Clásica. Estudios latinos, 9 (1995), pp. 67-101, especialmente pp. 72-73 y 93 .

${ }^{34}$ Roman d'Eneas, citado por Otto Söhring, «Werke bildender Kunst in altfranzösischen Epen», art. cit., p. 539.

${ }^{35}$ Ephraim Lessing, Laccoön; Nathan the Wise; Minna von Barnheim, trad. de William A. Steel, London, Everyman's Library, 1930, caps xvi-xix, esp. xix, p. 70.
} 


\section{Barry TAYLOR}

Toutes ces choses, que j'ay dictes,

Furent en la paroit escriptes

De la sale ou Fortune maint.

y anuncia que va a pasar de los persas a los griegos:

ay ceste oeuvre ci commenciee

et jusques ycy avanciee,

vueil dire des autres regnez,

comment ilz furent gouvernez ${ }^{36}$.

Pero ya no alude a las pinturas.

La écfrasis depara una visión privilegiada: que puede ser geográfica (los mapamundis), cósmica o temporal (es el caso de la profecía de Eneas).

La écfrasis, paradójicamente, no es necesariamente muy visual en sus efectos. Puede ser significativo que varios textos usen «ver» y «leer» indiscriminadamente para describir la acción del poeta-vidente (es el caso del $\mathrm{An}$ ticlaudianus o Pizan). Por ello, ¿cómo se deben imaginar los pasajes citados del Anticlaudianus que tratan de conceptos gramaticales como la elipsis?

En suma: el uso de la écfrasis se restringe a unos pocos géneros: la épica y el sueño-visión. Los objetos descritos corresponden a un corpus reducido: en la alegoría, la ropa de las personificaciones, sus casas, ${ }^{37}$ sus carros; en la épica, las armas, las tiendas y otros elementos militares.

\section{Textos castellanos medievales}

El Libro de Alexandre, siendo en parte una traducción creativa del Alexandreis latino y del Roman d'Alexandre francés, encaja perfectamente en los usos de la écfrasis descritos por Söhring ${ }^{38}$. Es el único ejemplo que puede citarse de écfrasis castellana anterior al siglo xv. En el Libro de Alexandre se dan cita los tópicos siguientes: el escudo (96), la profecía (97), el escudo de Aquiles con el cosmos (654 y siguientes), el carro de Darío (855-63), las armas de Darío (989), el sepulcro de Státira (1239), Babilonia (1519), la tumba de Alejandro (1791), el palacio de Poro (2119), el palacio de Febo y

${ }^{36}$ Christine de Pisan, Le Livre de la mutacion de Fortune, ed. cit., citas respectivamente, vv. 1172911731 y $11745-11748$.

${ }^{37}$ C. R. Patch, «The Dwelling-House of Fortune», en The Goddess Fortuna in Medieval Literature, Cambridge, MA, Harvard University Press, 1927, pp. 123-146.

${ }^{38}$ Otto Söhring, «Werke bildender Kunst in altfranzösischen Epen», art. cit. 
Diana (2477) y la tienda de Alejandro (2538). García López también nota la presencia de nada menos que cinco mapamundis ${ }^{39}$.

El Laberinto de Fortuna de Mena recoge varios aspectos presentes en los textos latinos y franceses citados arriba. El mapamundi de Mena (coplas 34-53) significa una visión privilegiada. La fuente es el De imagine mundi atribuido a San Anselmo. Pero cabe preguntarse de dónde tomó Mena la idea de incluir un mapamundi en un sueño-visión. Es posible que Mena deba este detalle a la tradicion esbozada en la primera parte de este estudio. Y también considero típico del poeta que no quisiera presentar el mapamundi como una écfrasis, como habían hecho tantos de sus antecesores, sino que decidiese revestirlo con el ropaje clásico del Somnium Scipionis ciceroniano.

En la Visión deleitable de Alfonso de la Torre (hacia 1454) las siete ciencias del trivio y el cuadrivio imparten sus disciplinas al niño Entendimiento. En una etapa más avanzada el Entendimiento conoce a Verdad, Razón y Sabiduría. Cada doncella lleva un vestido y habita una casa, las dos casas decoradas con doctrinas y figuras ejemplares. La casa de la Sabiduría está construida con materiales brillantes («la casa suya era fecha de una natura de piedras de balaxes e esmeraldas, en medio avia carbonculos e rubies de cantydad muy grande») y la de Naturaleza es «toda de alabastro muy liso labrado ${ }^{40}$. El discurso de Sabiduría está resumido en el espejo de Verdad: «la Verdad mostro en el espejo las causas naturales de las cosas siguientes. Primera mente el numero de los principios e las contrariedades de aquellos $[\ldots] \gg^{41}$. En la Parte II el autor usa menos la écfrasis: las virtudes cardinales (Prudencia, Justicia, Fortaleza y Templanza) enseñan verbalmente al Entendimiento, y la estructura ecfrástica se abandona.

Las personificaciones de las virtudes y ciencias (pero no sus casas) derivan del Anticlaudianus $^{42}$. Siguiendo la norma del género del sueño-visión, el autor es reacio a identificar a estos personajes. A la gramática se la nombra en una rúbrica «Fabla de la gramatica», pero en el texto mismo es simplemente «la doncella»:

\footnotetext{
${ }^{39}$ Todas las referencias proceden de Alexandre, ed. de Jorge García López, Barcelona, Crítica, 2010; sobre los cinco mapamundis, p. $162 \mathrm{n}$.

${ }^{40}$ Alfonso de la Torre, Visión deleytable, ed. de Jorge García López, Salamanca, Universidad de Salamanca, 1991, citas respectivamente, pp. 150 y 211. En una de las alegorías menores del Laberinto, la planicie del mundo «estava çercada de nítido muro, [...] trasparente, claríffico, puro»; el poeta alude a «la diáfana claror de los cantos» (copla 15), remito a Barry Taylor, «Las alegorías menores del Laberinto de Fortuna», en Bulletin of Hispanic Studies, 91 (2014), pp. 913-923.

${ }^{41}$ Alfonso de la Torre, Visión deleytable, ed. cit., p. 236.

${ }^{42}$ J. P. Wickersham Crawford, «The Seven Liberal Arts in the Vision delectable of Alfonso de la Torre», en Romanic Review, 4 (1913), pp. 66-72.
} 
entraron en una muy antygua e asaz bien hedeficada casa, en la qual abitava una asaz honesta donzella, en la mano derecha de la qual estava un tytulo escrito de letras latinas las quales dezian en esta manera: «Vox literata e articulada» $[\ldots]^{43}$.

La Visión es un buen ejemplo de dos tendencias mencionadas anteriormente. Mientras que las fórmulas matemáticas o figuras geométricas fácilmente pueden imaginarse inscritas en una pared, es difícil pensar cómo el Entendimiento «vio las naturas de los verbos» (343b, 374a). Ya hemos visto en otros textos la confusión entre ver y leer y la supuesta presentación visual de material irresolublemente verbal.

La influencia de la Visión Deleitable se acusa en un poeta de la escuela de Mena, Pero Guillén de Segovia. Su decir «Oyd maravillas del siglo presente», escrito hacia 1474, combina dos fuentes: la Visión y el Laberinto ${ }^{44}$. El niño Entendimiento y las siete Artes y sus casas son de clara procedencia torriana ${ }^{45}$. A diferencia de la Visión, las doncellas de Guillén, a excepción de Geometría cuya casa lleva pintadas las figuras de su arte (p. 369), imparten su doctrina de forma puramente verbal. En adición, cada casa contiene la rueda («cerco») de un Planeta, con los buenos levantados y los malos caídos en el suelo (al modo del Laberinto de Mena).

Si miras debajo daquesta mansion
Veras por el suelo gran gente caida
Los quales faltando la fe prometida
Pusieron su patria en gran perdicion ${ }^{46}$.

Si es cierto que Mena no da mucha importancia a describir claramente su esquema $^{47}$, Guillén es incluso más negligente. Para comprender que cada arte cuenta con una rueda en su casa, el lector depende de la rúbrica:

[Gramática] mostrole los verbos nombrados activos [...]

[Rúbrica: Porque de las artes liberales son siete casas finge el actor que en cada casa fallo uno de los Planetas]

${ }^{43}$ Alfonso de la Torre, Visión deleytable, ed. cit., p. 107. Sobre este principio genérico, véase Barry Taylor, «Santillana and Allegory», en Santillana: A Symposium, ed. de Alan Deyermond, Publications of the Medieval Hispanic Research Seminar, 28, London, Departament of Hispanic Studies, Queen Mary and Westfield College, 2000, pp. 39-51, especialmente pp. 47-48.

${ }^{44}$ Pero Guillén de Segovia, Obra poética, ed. de Carlos Moreno Hernández, Madrid, FUE, 1989, pp. 345-402.

${ }^{45}$ Francisco José Doménech Mira, «El decir "Oyd maravillas del siglo presente”, de Pero Guillén de Sevilla: contribución al estudio de sus fuentes literarias», en Dicenda, 5 (1986), pp. 13-45.

${ }^{46}$ Ibidem, p. 359.

${ }^{47}$ Barry Taylor, «Juan de Mena, la écfrasis y las dos fortunas: Laberinto de Fortuna, 143-208», art. cit., p. 174. 
De los siete cercos que son influyentes

Mostrole el primero do anda la luna

Y como en su casa la gente repu(g)na

La carne maldita y sus accidentes

Mostrole varones y dueñas prudentes

Guardar castidad en diversos modos

Mostrole pintados sus titulos todos

Tambien los pasados como los presentes ${ }^{48}$.

En el Triunfo del Marqués de Santillana de Diego de Burgos (1458), el poeta, guiado por Dante, sube el monte hasta el Otro Mundo, donde ve a los filósofos, oradores, poetas e historiadores ${ }^{49}$. La silla del Marqués ocupa las estrofas 58-60, pero sin écfrasis:
Segun que ya fueron en el Coliseo
que el padre de Tito ovo fundado
rencles de asientos ${ }^{50}$ por util arreo
asi alli eran en distinto grado.
En cada una silla un onbre asentado
que el acto mirava que alli se hazia
en medio de todas a todas vençia
aquella del noble marques memorado.
Lector no te pienses que fuese labrada
de obra muy rica de maçoneria
que otra lavor muy mas elevada
en gran maravilla mis ojos tenia.
El gozo sin par tanbien que sentia
de ver al señor que tanto la onrava
mi vista y sentido asi ocupava
que ál sino a él mirar no podia ${ }^{51}$.

\footnotetext{
${ }^{48}$ Francisco José Doménech Mira, «El decir “Oyd maravillas del siglo presente”, de Pero Guillén de Sevilla: contribución al estudio de sus fuentes literarias», art. cit., p. 354. En general, se supone que las rúbricas no son obra de los autores, pero quizás aquí estamos ante una excepción.

${ }^{49}$ Carlos Moreno Hernández, Retórica y humanismo: el Triunfo del Marqués de Santillana (1458), Valencia, Textos Lemir, 2008. [En línea]. Enlace: <http://parnaseo.uv.es/Lemir/Textos/Carlos_Moreno.pdf $>$ [Consulta: 11/03/2016].

${ }^{50}$ A nivel de microtexto, el parentesco entre Mena, Pero Guillén y Burgos se aprecia en su uso común de cierta expresión que aparece en sus écfrases: «rengles de sillas» (Coronación, xxxii), «rencle de sillas» (Pero Guillén, $n^{\circ} 26$, verso 139, p. 294), «rengles de asientos» (Burgos, p. 158, variante). La primera atestación de la palabra en Corde es de Mena. Enlace: < http://corpus.rae.es/cordenet.html > [Consulta: 11/03/2016].

${ }^{51}$ Carlos Moreno Hernández, Retórica y humanismo: el Triunfo del Marqués de Santillana (1458), ed. cit., estrofas 58-60, pp. 158-159.
} 
En cambio, la Cadira del Marqués (estrofas 229-230) presenta sus hechos:
Dentro en el templo ya todos estavan en sus convenibles y çiertos lugares
los cantos los imnos los sones çesavan con sus armonias atan singulares; e vi sobre quatro muy altos pilares muy bien fabricada una gran cadira tal que dira qualquier que la mira que vençe los rayos diurnos solares.
No fue la coluna del pio Antonino ni menos aquella del digno Trajano de tales entalles asi determino cortarase Fidias en verlos la mano. Sobravan en vista al oro indiano y en cada pilar estava esculpida gran parte de cosas que fizo en su vida el claro marques varon soberano ${ }^{52}$.

Diego de Burgos observa las normas ecfrásticas (brillantez de los materiales, superatio de los artistas de la antigüedad, escenas de la vida del homenajeado), pero no da más detalles de las hazañas del marqués.

Breve mención merece la relativa ausencia de la écfrasis y topotesia en el género del sueño-visión amoroso. Por ejemplo, para Garci Sánchez de Badajoz, autor del Infierno de enamorados (según la rúbrica «Coplas del dicho Garci Sanchez alos galanes fingiendo que los vido presos en la casa damor»), la casa es un simple recurso estructurante: lo que el poeta «ve» son los adeptos del Amor y no su casa ${ }^{53}$.

A mi modo de ver se nota cierta decadencia en la calidad de la écfrasis cuando entramos en la época del román. En sus primeros momentos el libro de caballerías se interesa muy poco por la écfrasis o topotesia: parece estar ausente del Caballero Zifar y en el Amadís la ordalía del Arco de los leales amadores se trata con brevedad y poco detalle visual (cap. 44). Quizás la causa de este cambio sea el rol que se atribuye a la écfrasis en la Hypnerotomachia Poliphili: en esta como en otras obras de los siglos XVI y XVII, su función es crear un ambiente de clasicismo o enigmático o maravilloso y su

\footnotetext{
${ }^{52}$ Ibidem, estrofas 229-230, p. 214.

${ }^{53}$ Cancionero de Garci Sánchez de Badajoz, ed. de Julia Castillo, Madrid, Editora Nacional, 1980, pp. 313-335.
} 
tratamiento es episódico. Lo mismo se puede decir del Palacio de Felicia (Montemayor, La Diana IV) ${ }^{54}$; los libros de caballerías del siglo $\mathrm{XVI}^{55}$; y los palacios (entre ellos el Museo del Discreto con sus paredes diáfanas) en el Criticón de Gracián (II iv) ${ }^{56}$.

\section{Conclusiones}

Para concluir, comparemos los textos castellanos con los extrapirenaicos. En la tradición de la épica clásica, hay una línea de influencia que lleva de Homero, pasando por Virgilio, a Ercilla ${ }^{57}$. En la España medieval, el único representante de la écfrasis épica es el Alexandre. (A no ser que se interprete el mapamundi del Laberinto de Fortuna como un disfrazado tópico épico).

Durante el siglo XV el caldo de cultivo de la écfrasis es la poesía alegórica extensa $^{58}$. En estos dos géneros, la écfrasis debe definirse con más amplitud que la simple descripción verbal de una obra de arte: dichos objetos son siempre significativos, metatextos que contienen de forma simbólica información que comenta el marco en que se integran.

La maravilla es una constante: la literatura de la Edad Media no describía cosas cotidianas. Söhring cataloga muchas descripciones ideadas para asombrar al lector pero no para arrojar luz sobre el texto que las enmarca ${ }^{59}$. Con los romans de fecha más reciente, empezando con la Hypnerotomachia Poliphili, los autores vuelven a una época más temprana de la écfrasis: el misterio y la maravilla son moneda corriente, pero la écfrasis como metatexto, contenedor de la sabiduría, se ha dejado atrás.

Recibido: $17 / 03 / 2016$

Aceptado: 15/06/2016

\footnotetext{
${ }^{54}$ Gustavo Correa, «El templo de Diana en la novela de Jorge de Montemayor», en Thesaurus, 16 (1961), pp. 59-76.

${ }^{55}$ Como botón de muestra, véase Jesús Duce García, «Fantasías caballerescas: aproximación al motivo de los castillos encantados», en Actas del IX Congreso Internacional de la Asociación Hispánica de Literatura Medieval (A Coruña, 18-22 de septiembre de 2001), ed. de M. Pampín y C. Parrilla, 2 vols., A Coruña, Universidade de A Coruña - Departamento de Filoloxia Española e Latina - Toxosoutos, 2005, II, pp. 213-232.

${ }^{56}$ Jorge Checa, Gracián y la imaginación arquitectónica, Potomac, Scripta Humanistica, 1996. Antonio Armisén, «Admiración y maravillas en El Criticón (más unas notas cervantinas)», en Gracian y su época. Actas de la I reunión de filólogos aragoneses, Zaragoza, Institución Fernando el Católico, 1986, pp. 201-242, apunta que para Gracián las obras del hombre -a diferencia de las obras de Dios- no son maravillosas, véanse especialmente pp. 221-223 y 237.

${ }^{57}$ Remito a Vicente Cristóbal, «De la Eneida a la Araucana», art. cit.

${ }^{58}$ Diane Chaffee, «Ekphrasis in Juan de Mena and the Marqués de Santillana», en Romance Philology, 35:4 (1982), pp. 609-616.

${ }^{59}$ Otto Söhring, «Werke bildender Kunst in altfranzösischen Epen», art. cit.
} 
$\cos 8$

LA ÉCFRASIS EN EL SIGLO XV: MARAVILLA, METATEXTO Y ALEGORÍA

Resumen: La écfrasis, definida como la descripción verbal de un objeto de arte visual, no se contemplaba en la retórica como un género aparte. Sus efectos se trataban como parte de la enargeia o evidentia, cuya intención es poner una escena delante de los ojos del lector. Aunque falta de status teórico, la práctica ecfrástica tiene una presencia en los textos mismos desde tiempos de Homero. En este estudio se pasa revista a un corpus de textos no hispánicos para establecer los tópicos recurrentes del género. Se pasa a continuación al examen de ciertas obras hispanas del s. Xv.

Palabras Clave: Écfrasis. Alegoría. Metatexto. Marco. Sueño-visión. Maravilla.

\section{EkPhrasis in the Fifteenth Century: Marvel, MetateXt and Allegory}

ABSTRACT: Ekphrasis, defined as the verbal description of a visual work of art, was not regarded in rhetoric as a separate genre. Its effects were studied as part of enargeia or evidentia, intended to place a scene before the reader's eyes. Despite this lack of theoretical status, the practice of ekphrasis has had a presence in the texts themselves since the time of Homer. In this study a corpus of non-Hispanic texts is surveyed in order to establish the recurrent topics of the genre. This is followed by an analysis of certain Spanish texts of the fifteenth century.

Keywords: Ekphrasis. Allegory. Metatext. Frame. Dream-Vision. Wonder. 